\title{
Anaemia among Pregnant Women Attending Antenatal Care in Kyenjojo and Kole Districts in Uganda: Prevalence and Associated Factors
}

\author{
James Ssekitooleko ${ }^{1 *}$, Tinuola Femi Rufus ${ }^{2}$, Denis Mubiru ${ }^{3}$, Catherine Nyakakye ${ }^{3}$, Paul \\ Kibikyabu $^{4}$ \\ ${ }^{1}$ PhD in Public Health, Texila American University, Uganda \\ ${ }^{2}$ Federal University, Gusau Zamfara State, Nigeria \\ ${ }^{3}$ Malaria Consortium, Juba, South Sudan \\ ${ }^{4}$ Kyenjojo District Local Government, Kyenjojo, Uganda
}

\begin{abstract}
Anemia during pregnancy is a major public health problem, with a global prevalence of $41.8 \%$. It is associated with high morbidity and mortality. Information on the prevalence of anemia and associated factors among pregnant women in the study area is limited. This study aimed at determining the prevalence and predictors of anemia among pregnant women attending antenatal clinics (ANC) in Kyenjojo and Kole Districts, Uganda. Cross-sectional study was conducted among randomly selected pregnant women. Quantitative data was collected using a structured questionnaire that captured demographic and obstetric characteristics. Haemoglobin concentration $(\mathrm{Hb})$ was determined using HemoCue 201. The study outcome was the prevalence of anaemia ( $\mathrm{Hb}<11 \mathrm{~g} / \mathrm{dl})$. Chi-square, odds ratio, and logistic regression were used to test for associations. Of the total 760 pregnant women who participated in this study, $20.1 \%$ were anaemic. The prevalence varied from $13.4 \%$ in Kyenjojo to 26.9\% in Kole District. Of 153 anaemic women, 121 (97\%) were mildly anaemic, 27 (18\%) moderately anemic, and 5(3\%) severely anemic. Malaria infection [AOR: 0.46, 95\% CI (0.26 - 0.83)], primigravida [AOR: 0.52, 95\% CI: 0.29-0.93], and residing in Kole [AOR: 0.50, 95\% CI: 0.32-0.76] were significant predictors of low haemoglobin concentration. This study highlighted the high prevalence of anaemia in our settings and the significant association between anaemia and malaria among pregnant women. Therefore, routine screening of pregnant women for anemia, malaria, and other risk factors during their first ANC visit is recommended to identify those at risk and prompt management provided to curb their negative consequences.
\end{abstract}

Keywords: Antenatal care, Anaemia in pregnancy, Malaria infection, Pregnant women, Uganda.

\section{Introduction}

Anaemia is a global public health problem and most times under-unrecognized as it is overshadowed by the normal physiological condition during pregnancy [1]. It is a risk factor in pregnancy and is a major cause of morbidity and mortality among pregnant women lowincome and negative consequences to fetus including premature births, low birth weight and death [2]. According to 2008 World Health Organization report, the highest rate of anaemia during pregnancy was found in the Sub-Saharan region, with over 17.2 million mothers were estimated to be anaemic and accounting for $30 \%$ of global cases [2,3]. In Africa, more than three percent of maternal mortality are attributed to maternal anaemia [4]. In the East-African region, the prevalence of anaemia among pregnant women varies from $23.36 \%$ in Rwanda, $38.2 \%$ in Uganda, $57.1 \%$ in Tanzania, and $57-$ $61 \%$ in Kenya [5, 6, 7, 8]. According to Uganda's Demographic and Health Surveys report 2016, the prevalence of anemia among pregnant 
women was $38 \%$ in 2016 but with regional variations from $39.3 \%$ in Lago region Northern Uganda, 29.4\% in Tooro region Mid-Western Uganda, and $16.9 \%$ in Kigezi region [9].

The cause of anemia during pregnancy is multifactorial. It includes nutritional deficiencies of minerals (like iron, folate, and vitamin B12), and parasitic diseases (like malaria and hookworm), and chronic infections (like tuberculosis and HIV). The contribution of each of these risk factors to anaemia during pregnancy varies greatly by location, season, and dietary [10]. In the literature, wealth index, maternal education, maternal age, parity, area of residence, occupation, iron intake, source of water, and marital status were factors associated with anemia in pregnancy $[11,12]$.

Though there are pieces of evidence in Uganda regarding the anaemia prevalence and the risk factors associated with it, none of these indicated the overall burden and risks among pregnant women in Kole and Kyenjojo Districts. And knowing the prevalence is useful in the intervention mix to lessen the case burden of anaemia and importantly, aid in monitoring the progress made in reproductive health. Thus, the objective of this study was to determine the prevalence and factors associated with anemia among pregnant women who sought antenatal care (ANC) in the Kole (Northern Uganda) and Kyenjojo (Midwestern Uganda) District in Uganda. The findings are vital in the design of policies and strategies aimed at reducing the burden of anemia during pregnancy and hence lowering the maternal mortality ratio in the Ugandan context.

\section{Materials and Methods}

\section{Study Setting}

We conducted a multi-centre facility-based study among pregnant women attending their first antenatal care clinics in Alito HC III and Bala HC III located in Kole District, Northern Uganda, and in Katooke HC III and Butunduzi HC III located in Kyenjojo District mid-western Uganda. Kole District is in Northern Uganda, with a population estimate of 297,479 . It has 19 health facilities. In 2020, 14,458 and 21,716 pregnant women attended their first ANC visit in Kole and Kyenjojo Districts, respectively.

\section{Design}

A cross-sectional quantitative research design was adopted. A structured questionnaire was used to collect data from pregnant women. Laboratory samples were collected to estimate haemoglobin level and test for the presence of malaria parasites and HIV.

\section{Sample Size Determination and Sampling Technique}

The sample size of this study was calculated by using the Kish Leslie formula. We considered 95\% confidence interval, 5\% margin of error, and $45 \%$ and $64 \%$ prevalence of anaemia for Kole (Northern Uganda) and Kyenjojo (MidWestern Uganda), respectively [9]. A factor of $10 \%$ non-response rate was added. The four facilities were purposively sampled due to the high volume/patient load in each of the 2 districts. A total sample size of 760 pregnant woman were selected using a systematic random sampling technique to avoid selection bias. The national HMIS form 071: integrated antenatal register was used as the sampling frame. After randomly selecting the start point, thereafter every third unit in the list was included until the required sample size was attained.

\section{Data Collection}

A pre-tested structured questionnaire was administered by trained midwives to obtain information on maternal characteristics such as age, education level, occupation, marital status, HIV status, gravidity, gestational age, history of abortion, and use of malaria prevention methods (IPTp-SP and ITNs). Gestation age was estimated using the date of the last normal menstrual period. Study variables included in the questionnaire were guided by previous studies in Uganda [12-14]. Finger pricked blood samples were taken to measure haemoglobin concentration using HemoCue ${ }^{\circledR} 201$ machine, 
detect the presence of malaria parasite, and HIV testing by trained Phlebotomist. Pregnant women with a haemoglobin concentration of less than $11.0 \mathrm{~g} / \mathrm{dl}$ were categorised as anaemic using the WHO classification [15]. Anaemia was considered severe when haemoglobin concentration was less than $7.0 \mathrm{~g} / \mathrm{dL}$, moderate when haemoglobin was between 7.0 and 9.9 $\mathrm{g} / \mathrm{dL}$, and mild from 10 to $10.9 \mathrm{~g} / \mathrm{dL}$.

\section{Data Management and Analysis}

Quantitative data was collected using ODK software, exported to Microsoft Excel, and then transferred to STATA version 15 statistical package for further analysis. The outcome variable for this study was anaemia (low $\mathrm{Hb}$ concentration). The independent variables include socio-demographic factors (age, marital status, educational status, and occupational status); obstetric factors (gravidity, parity, trimester of pregnancy, history of abortion); health-related conditions (malaria infection, HIV); and malaria prevention measures (ITN ownership and use). Descriptive statistics were done to explain the study population in relation to relevant variables. Both bi-variate and multivariate logistic regressions were used to assess the association. Odds ratios generated were used to reflect the likelihood of risk factors to anaemia prevalence in pregnant women.

\section{Ethical Approval}

Mildmay Uganda Institutional Review Committee (REF 0209-2020), Uganda National Council for Science and Technology, and University Ethical committee Texila American University Guyana approved the study. Written informed consent was obtained from all study participants. Data collected from each participant and results of laboratory tests were kept confidential.

\section{Results}

A total of 760 pregnant women (379 in Kole and 381 in Kyenjojo) were included in this study, with a response rate of $99 \%$. The age of the participants ranged from 15 to 46 years with a median age of 23 , the majority (41.1\%) of them between 20-24 years. The majority (94.5\%) of the women were married, and about $77 \%$ of the women completed their primary and secondary level education, and $97 \%$ were farmers. Sixtynine percent of the mothers were multigravidae, $50.36 \%$ of them were in their second trimester for their first ANC visit. Over $85 \%$ of pregnant women owned at least one ITN (Table 1).

Table 1. Sociodemographic and Obstetric Characteristics of Study Participants

\begin{tabular}{|c|c|c|c|c|c|c|}
\hline \multirow[t]{2}{*}{ Characteristics } & \multicolumn{2}{|c|}{ Kole $(\mathrm{N}=379)$} & \multicolumn{2}{|c|}{ Kyenjojo (N=381) } & \multicolumn{2}{|c|}{ Total $(\mathrm{N}=760)$} \\
\hline & Frequency & Percent $(\%)$ & Frequency & Percent (\%) & Freq & Percent $(\%)$ \\
\hline \multicolumn{7}{|l|}{ Age } \\
\hline Median & - & - & - & - & 23 & - \\
\hline Min & 15 & - & 15 & - & 15 & - \\
\hline $\operatorname{Max}$ & 46 & - & 40 & - & 46 & - \\
\hline Mean & 24 & - & 25 & - & 24 & - \\
\hline \multicolumn{7}{|l|}{ Age Group } \\
\hline$\leq 19$ & 88 & 23.2 & 58 & 17.9 & 156 & 20.5 \\
\hline $20-24$ & 153 & 40.4 & 159 & 41.6 & 312 & 41.1 \\
\hline $25-29$ & 80 & 21.1 & 76 & 20.0 & 156 & 20.5 \\
\hline $30-34$ & 36 & 9.5 & 48 & 12.6 & 84 & 11.1 \\
\hline$\geq 35$ & 22 & 5.8 & 30 & 7.9 & 52 & 6.8 \\
\hline \multicolumn{7}{|l|}{ Occupation } \\
\hline Farmers & 368 & 97.1 & 323 & 84.8 & 691 & 90.9 \\
\hline Traders/Professional & 11 & 2.9 & 30 & 7.8 & 41 & 5.4 \\
\hline
\end{tabular}




\begin{tabular}{|c|c|c|c|c|c|c|}
\hline Unemployed & 0 & 0.0 & 28 & 7.4 & 28 & 3.7 \\
\hline \multicolumn{7}{|l|}{ Education Level } \\
\hline None & 90 & 23.7 & 86 & 22.6 & 176 & 23.2 \\
\hline Primary & 266 & 70.2 & 228 & 59.8 & 494 & 65.0 \\
\hline Secondary or Higher & 23 & 6.1 & 67 & 17.6 & 90 & 11.8 \\
\hline \multicolumn{7}{|l|}{ Marital status } \\
\hline Not married & 4 & 1.1 & 38 & 10.0 & 42 & 5.5 \\
\hline Married & 375 & 98.9 & 343 & 90.0 & 718 & 94.5 \\
\hline \multicolumn{7}{|l|}{ Gravidity } \\
\hline Primigravidae & 142 & 37.5 & 91 & 23.9 & 233 & 30.7 \\
\hline Multigravidae & 237 & 62.5 & 290 & 76.1 & 527 & 69.3 \\
\hline \multicolumn{7}{|l|}{ Trimester } \\
\hline $1 \mathrm{st}$ & 186 & 49.1 & 126 & 33.1 & 312 & 41.0 \\
\hline 2nd & 168 & 44.3 & 214 & 56.2 & 382 & 50.3 \\
\hline $3 \mathrm{rd}$ & 25 & 6.6 & 41 & 10.7 & 66 & 8.7 \\
\hline \multicolumn{7}{|l|}{ ITN ownership } \\
\hline Owned At least 1 ITN & 337 & 89 & 316 & 83 & 653 & 86 \\
\hline Did not own any ITN & 42 & 11 & 65 & 17 & 107 & 14 \\
\hline
\end{tabular}

\section{Prevalence of Anaemia among Pregnant Women}

A total of $153(20.1 \%)$ pregnant women were anaemic. The prevalence of anemia in Kole was 26.9\% (102/379), and that in Kyenjojo was $13.4 \%$ (51/381). Of 153 anaemic women; 121 (97\%) were mildly anaemic, 27 (18\%) moderately anemic, and 5(3\%) severely anemic. The prevalence of mild, moderate, and severe anaemia in Kole was $21 \%, 5 \%$, and $0.8 \%$ respectively, and in Kyenjojo $11 \%, 2 \%$, and $0.5 \%$, respectively. Anaemia was more prevalent in the younger age $(15-19$ years $)$ decreased with increasing age (Figure.1).

The error bars in Figure 1 represent 95\% confidence intervals. Mild anaemia $(\mathrm{Hb}=10$ $10.9 \mathrm{~g} / \mathrm{dL})$, Moderate anaemia $(\mathrm{Hb}=7-9.9 \mathrm{~g} / \mathrm{dl})$, Severe anaemia $(\mathrm{Hb}<7 \mathrm{~g} / \mathrm{dL})$.

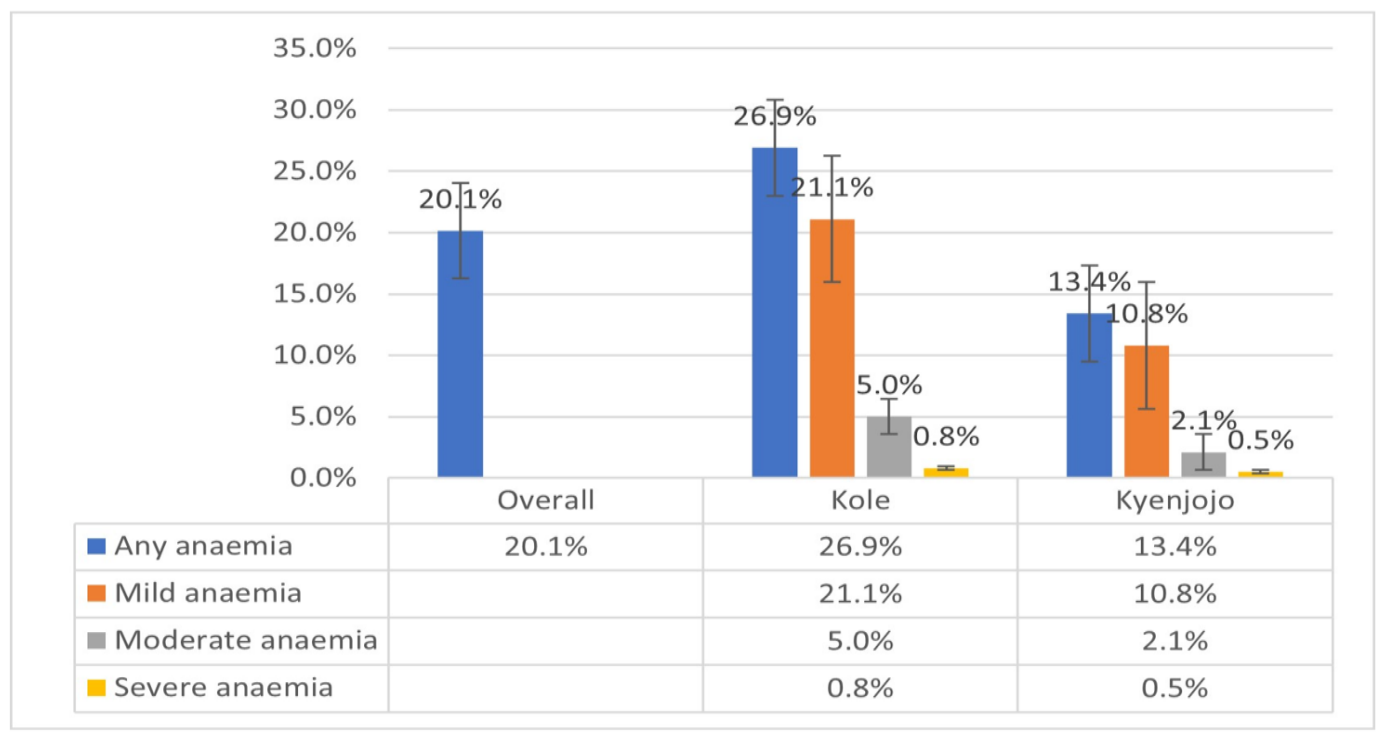

Figure 1. Overall Prevalence and Severity of Anaemia among Pregnant Women 
Bi-variate Analysis of Factors associated with Anaemia among Pregnant Women

Anaemia was significantly associated with the mother's age, gravidity, gestation age, presence of malaria parasites, not using ITN, and place of residence. Other variables (including marital status, educational level attained, occupation, owning an ITN, or HIV status) yielded no significant association (Table 2 and Table 3).

Table 2. Bivariate analysis for socio-demographic factors associated with Anaemia among pregnant women

\begin{tabular}{|c|c|c|c|c|c|c|}
\hline \multirow{4}{*}{$\begin{array}{l}\text { Socio-demographic } \\
\text { characteristics }\end{array}$} & \multicolumn{2}{|l|}{ Total } & \multicolumn{2}{|l|}{ Kole District } & \multicolumn{2}{|c|}{ Kyenjojo District } \\
\hline & \multicolumn{2}{|l|}{ Anaemia } & \multicolumn{2}{|l|}{ Anaemia } & \multicolumn{2}{|l|}{ Anaemia } \\
\hline & Positive & \multirow[t]{2}{*}{ p-value $* *$} & Positive & \multirow[t]{2}{*}{ p-value ${ }^{* *}$} & Positive & \multirow[t]{2}{*}{ p-value ${ }^{* * *}$} \\
\hline & $\mathbf{N}(\%)$ & & $\mathbf{N}(\%)$ & & $\mathbf{N}(\%)$ & \\
\hline \multicolumn{7}{|l|}{ Age group (years) } \\
\hline$\leq 19$ & $47(30.13)$ & \multirow{5}{*}{$P=0.003$} & $36(40.91)$ & \multirow[t]{5}{*}{$P=0.002$} & $11(16.18)$ & \multirow[t]{5}{*}{$P=0.937$} \\
\hline $20-24$ & 57 (18.27) & & $36(23.53)$ & & $21(13.21)$ & \\
\hline $25-29$ & $33(12.15)$ & & $23(28.75)$ & & $10(13.16)$ & \\
\hline $30-34$ & $10(11.90)$ & & $5(13.89)$ & & $5(10.42)$ & \\
\hline$\geq 35$ & $6(11.54)$ & & $2(9.09)$ & & $4(13.33)$ & \\
\hline \multicolumn{7}{|l|}{ Age (years) } \\
\hline Adolescents (15-19) & $47(30.1)$ & \multirow[t]{2}{*}{$P<0.001 * *$} & $36(40.91)$ & \multirow[t]{2}{*}{$P<0.001 * *$} & $11(16.18)$ & \multirow[t]{2}{*}{$P=0.456$} \\
\hline Adults $(\geq 20)$ & $106(17.6)$ & & $66(22.68)$ & & $40(12.78)$ & \\
\hline \multicolumn{7}{|l|}{ Residence/District } \\
\hline Kole & $102(26.91)$ & \multirow[t]{2}{*}{$P<0.001 * *$} & - & - & - & - \\
\hline Kyenjojo & $51(13.39)$ & & - & - & - & - \\
\hline \multicolumn{7}{|l|}{ Marital status } \\
\hline Not married & $8(19.1)$ & \multirow[t]{2}{*}{$P=0.857$} & $1(25.00)$ & \multirow[t]{2}{*}{$P=0.706$} & $7(18.42)$ & \multirow[t]{2}{*}{$P=0.32$} \\
\hline Married & $145(20.2))$ & & $101(26.93)$ & & $44(12.83)$ & \\
\hline \multicolumn{7}{|l|}{ Educational level } \\
\hline No education & $29(16.48)$ & \multirow[t]{3}{*}{$P=0.293$} & $20(22.22)$ & \multirow[t]{3}{*}{$P=0.41$} & $9(10.47)$ & \multirow[t]{3}{*}{$P=0.635$} \\
\hline Primary level & $107(21.66)$ & & $74(27.82)$ & & $33(14.47)$ & \\
\hline Secondary \& higher & $15(17.86)$ & & $7(35.00)$ & & $8(12.5)$ & \\
\hline \multicolumn{7}{|l|}{ Occupation } \\
\hline Farmer & $142(20.55)$ & \multirow[t]{3}{*}{$P=0.635$} & $100(27.17)$ & \multirow[t]{3}{*}{$P=0.734$} & $42(13.00)$ & \multirow[t]{3}{*}{$P=0.775$} \\
\hline Traders/Professional & $7(17.07)$ & & $2(18.18)$ & & $5(16.67)$ & \\
\hline Unemployed & $4(14.29)$ & & $0(0.00)$ & & $4(14.29)$ & \\
\hline
\end{tabular}

Note: Row percent used, $* *$ Pearson's chi square test at alpha $=0.05, \mathrm{~N}$ values are weighted 
Table 3. Bivariate Analysis for Obstetric and Health-Related Factors Associated with Anaemia among Pregnant Women

\begin{tabular}{|c|c|c|c|c|c|c|}
\hline \multirow{3}{*}{$\begin{array}{l}\text { Obstetric } \\
\text { Characteristics }\end{array}$} & \multicolumn{2}{|l|}{ Total } & \multicolumn{2}{|l|}{ Kole District } & \multicolumn{2}{|c|}{ Kyenjojo District } \\
\hline & \multicolumn{2}{|l|}{ Anaemic } & \multicolumn{2}{|l|}{ Anaemic } & \multicolumn{2}{|l|}{ Anaemic } \\
\hline & Yes N (\%) & p-value $* *$ & Yes N $(\%)$ & p-value** & Yes N $(\%)$ & p-value** \\
\hline \multicolumn{7}{|l|}{ Gravidity } \\
\hline Primigravidae & $71(30.47)$ & \multirow[t]{2}{*}{$P<0.001$} & $52(36.62)$ & \multirow[t]{2}{*}{$P=0.001$} & $19(20.88)$ & \multirow[t]{2}{*}{$P=0.016$} \\
\hline Multigravidae & $82(15.56)$ & & $50(21.10)$ & & $32(11.03)$ & \\
\hline \multicolumn{7}{|l|}{ Gestation period } \\
\hline First Trimester & $77(24.68)$ & \multirow[t]{3}{*}{$P<0.022$} & $55(29.57)$ & \multirow[t]{3}{*}{$P=0.452$} & $22(17.46)$ & \multirow[t]{3}{*}{$P=0.025$} \\
\hline Second Trimester & $62(16.23)$ & & $42(25.00)$ & & $20(9.35)$ & \\
\hline Third Trimester & $14(21.21)$ & & $5(20.00)$ & & $9(21.95)$ & \\
\hline \multicolumn{7}{|l|}{ HIV serostatus } \\
\hline Positive & $2(25.00)$ & \multirow[t]{2}{*}{$P<0.665$} & $2(25.00)$ & \multirow[t]{2}{*}{$P=0.631$} & - & \multirow[t]{2}{*}{-} \\
\hline Negative & $151(20.08)$ & & $100(26.95)$ & & - & \\
\hline \multicolumn{7}{|l|}{ Malaria infection } \\
\hline Positive & $36(42.86)$ & \multirow[t]{2}{*}{$P<0.001 * *$} & $26(44.83)$ & \multirow[t]{2}{*}{$P=0.001$} & $10(38.46)$ & \multirow[t]{2}{*}{$P<0.001$} \\
\hline Negative & $117(17.31)$ & & $76(23.68)$ & & $41(11.55)$ & \\
\hline \multicolumn{7}{|l|}{ ITN ownership } \\
\hline Yes & $133(20.37)$ & \multirow[t]{2}{*}{$P=0.689$} & $90(26.71)$ & \multirow[t]{2}{*}{$P=0.797$} & $43(13.61)$ & \multirow[t]{2}{*}{$P=0.779$} \\
\hline No & $20(18.69)$ & & $12(28.57)$ & & $8(12.31)$ & \\
\hline \multicolumn{7}{|c|}{ Number of ITN owned } \\
\hline None & $20(18.69)$ & \multirow[t]{4}{*}{$P=0.099$} & $12(28.57)$ & \multirow[t]{4}{*}{$P=0.033$} & $8(12.31)$ & \multirow[t]{4}{*}{$P=0.193$} \\
\hline One & $70(24.73)$ & & $48(34.53)$ & & $22(15.28)$ & \\
\hline Two & $35(16.28)$ & & $26(24.53)$ & & $9(8.26)$ & \\
\hline Three \& more & $28(18.06)$ & & $16(17.39)$ & & $12(19.05)$ & \\
\hline \multicolumn{7}{|l|}{ ITN Use } \\
\hline Yes & $117(18.31)$ & $P=0.016$ & $77(24.84)$ & $P=0.009$ & $40(13.61)$ & $P=0.53$ \\
\hline No & $16(34.04)$ & & $13(48.15)$ & & $3(15.00)$ & \\
\hline
\end{tabular}

Note: Row percent used, ** Pearson's chi square test at alpha $=0.05, \mathrm{~N}$ values are weighted

\section{Multi-variate Analysis of Factors associated with Anaemia among Pregnant Women}

Multiple logistic regression analysis was performed to identify independent predictors of anaemia among pregnant women. Eight explanatory variables that were associated with anaemia in bivariable analyses at $10 \%$ level of significance were entered into multiple logistic regression models. Area of residence, gravidity, and malaria infection showed significant association with anaemia. Accordingly, staying in Kyenjojo district had a 50\% (AOR: 0.50, 95\% CI: 0.32-0.76) protected effect against being anaemic compared to pregnant women in the Kole district. Multigravidae 48\% (AOR: 0.52, 95\% CI: 0.29-0.93) less likely to be anaemic compared to Primigravidae while women with malaria parasite had a 54\% (AOR: $0.46,95 \% \mathrm{CI}$ : $0.25-0.82$ ) chance of suffering from anaemia compared to those without parasitemia. Anemia was rampant among young pregnant women aged $\leq 19$ years. Pregnant women aged 20 years or more were less likely to be anaemic compared to young pregnant women aged $\leq 19$ years of age. Although older women were less likely to be anaemic, such an association did not reach a statistically significant level (Table 4). 
Table 4. Multi-variate Analysis for determinant factors associated with Anaemia among Pregnant Women

\begin{tabular}{|c|c|c|c|c|c|c|}
\hline \multirow[t]{2}{*}{ Factors } & \multicolumn{3}{|c|}{ Crude Estimates } & \multicolumn{3}{|c|}{ Adjusted Estimates } \\
\hline & OR & $95 \% \mathrm{CI}$ & p-value & aOR & $95 \% \mathrm{CI}$ & p-value \\
\hline \multicolumn{7}{|l|}{ Age in years } \\
\hline Adolesents (15-19) & 1 & - & - & - & - & - \\
\hline Adults (>20 yrs) & 0.49 & $0.33-0.74$ & $P<0.001$ & - & - & - \\
\hline \multicolumn{7}{|l|}{ Location } \\
\hline Kole & 1 & - & - & 1 & - & - \\
\hline Kyenjojo & 0.42 & $0.29-0.61$ & $P<0.001$ & 0.50 & $0.32-0.76$ & $P=0.001$ ** \\
\hline \multicolumn{7}{|l|}{ Gravidity } \\
\hline Primigravidae & 1 & - & - & 1 & - & - \\
\hline Multigravidae & 0.42 & $0.29-0.61$ & $P<0.001$ & 0.52 & $0.29-0.93$ & $P=0.026$ \\
\hline \multicolumn{7}{|l|}{ Gestation period } \\
\hline First Trimester & 1 & - & - & 1 & - & - \\
\hline Second Trimester & 0.59 & $0.41-0.86$ & $P=0.006$ & 0.83 & $0.54-1.28$ & $P=0.403$ \\
\hline Third Trimester & 0.82 & $0.43-1.56$ & $P=0.55$ & 1.51 & $0.71-3.25$ & $P=0.286$ \\
\hline \multicolumn{7}{|l|}{ Malaria infection } \\
\hline Positive & 1 & - & - & 1 & - & - \\
\hline Negative & 0.28 & $0.17-0.45$ & $P<0.001$ & 0.46 & $0.26-0.83$ & $P=0.01$ \\
\hline \multicolumn{7}{|l|}{ ITN Use } \\
\hline Yes & 1 & - & - & 1 & - & - \\
\hline No & 2.16 & $1.14-4.08$ & $P=0.018$ & 1.74 & $0.89-3.41$ & $P=0.103$ \\
\hline
\end{tabular}

Note: Row percent used, ** Pearson's chi square test at alpha $=0.05, \mathrm{~N}$ values are weighted

\section{Discussion}

Anemia is the commonest medical complication in pregnancy, affecting up to an estimated $40 \%$ of pregnant women compared to $29 \%$ of all women of reproductive age globally $[1,16]$. Despite anemia being a public health concern, women in low developed countries are disproportionately affected. In 2011, WHO reported that Africa had the highest prevalence of anemia of $37.6 \%$ [2]. Thus, this study assessed the prevalence and determinants of anemia among pregnant women in Kyenjojo and Kole Districts in Uganda. In our study, the overall prevalence of anaemia was $20.1 \%$ which indicates that anemia among pregnant women is a major public health problem in Uganda. This finding agrees with findings in Uganda, Kenya, Ethiopia, and Nigeria, [13, 17, 18, 19]. However, this finding was lower than those reported from the systematic review and meta-analysis in
Uganda [12, 20] and in East Africa [5], other studies in the region [9, 21], and the WHO estimate of 40-60\% in developing countries [1]. The prevalence in this study was higher than the studies conducted in Uganda [9, 14, 22], Ethiopia [23], and Saudi Arabia [24]. The variations in the prevalence of anaemia were attributed to differences in the socioeconomic status of the different populations studied, a factor that determines nutrition and health-being. In addition, the variation can be explained by the range of interventions employed to address anaemia in pregnancy vary in different settings [25]. Importantly, the prevalence of mild, moderate, and severe anemia was $15.9 \%, 3.6 \%$ and $0.7 \%$, respectively. The low prevalence of severe anemia is consistent with earlier reports [13]. The prevalence of anaemia was significantly higher in Kole than in Kyenjojo (P $<0.001)$. Kole district fall in region in Northern Uganda that was ravaged by the civil war that 
left most of the social services in the region in ruins and a large majority of its population in poverty [26]. The above is collaborated by the findings from the 2016 Uganda Demographic and Health Surveys [9], which showed $43 \%$ of the population in Acholi region were in the lowest wealth quartile compared to $6.4 \%$ in Tooro region. A Study reported an association of anaemia and wealth with mothers in lowest wealth quartile at higher risk, this finding can explain why anaemia prevalence was more in Kole [17]. In addition, the observed difference in prevalence can be explained by high hookworm infection in Northern Uganda [27].

The causes of anemia in pregnancy are complex, and several predisposing factors have been implicated. In this study, we found an association between anemia and area of residence, parity, and the presence of malaria parasites. In the multi-variate logistic analysis, pregnant women who had been infected with malaria were more likely to be anemic (AOR: $0.46,95 \%$ CI: $0.25-0.82$ ). The association is supported by a systematic review [28, 29, 30] and other studies in Uganda [31], Ethiopia [32], Ghana [33], and Sudan [34]. The study findings add evidence to further support the association of malaria with anemia during pregnancy. Malaria in pregnancy may causes anemia through hemolysis of infected and uninfected red blood cell, increased splenic clearance of erythrocytes, and reduced red blood cell production. Malaria-associated maternal anemia is the leading cause of maternal and fetal morbidity and mortality [35]. Malaria transmission in Uganda is perennial, with two peaks following rainy seasons. The data collection for this study was done during the high malaria transmission season. Therefore, this might contribute to the association of malaria with anemia.

In this study, being multigravidae was associated with lower odds of anemia in pregnancy (AOR: 0.52, 95\% CI: 0.29-0.93). In addition, the prevalence of anaemia decreased with increasing parity. These findings contradict results from studies elsewhere. For example, in
Ethiopia, Kibret et al. 2021 documented an increased odds of anaemia associated with high gravidity [17]. Other studies in Uganda [21], Sudan [34], Ethiopia [23], and Iran [36] also found an increased risk of anaemia with parity four or more. The timing of ANC initiation is critical for commencement of interventions and services routinely offered to pregnant women at ANC clinics to prevent anaemia, such as folic acid supplementation, provision of LLINs, and IPT dosing as well as laboratory investigations to diagnose early anaemia in pregnancy and offer early treatment. In our study, 50\% of the mothers initiated their ANC in their second trimester, and the prevalence of anaemia was more among mothers in their $1^{\text {st }}$ and $3^{\text {rd }}$ trimester. However, this yielded no association with anaemia. These results contradict findings from Uganda, Tanzania, Kenya, and South Africa that found the odds of having anaemia in pregnancy were significantly higher among pregnant women who initiated ANC $2^{\text {nd }}$ and $3^{\text {rd }}$ trimester [6, 7, 17, 21].

\section{Limitations}

The results of this study ought to be interpreted in light of the following shortfalls; a) We did not investigate other causes of anemia like nutritional factors, soil-transmitted helminthes infection, and hereditary conditions such as sickle cell disease, b) Other demographic factors such as body mass index, smoking and wealth index were not elucidated, and c) crosssectional study like ours, does not provide inform on whether the pregnant mothers had anemia before conception; on this basis, we presumed that the anemia diagnosed was pregnancy-related.

\section{Conclusion}

Two in 10 pregnant women (20\%) seeking their first antenatal care were anaemic making anaemia in pregnancy a public health problem in the study districts. The prevalence of anaemia in pregnant women in Kole was higher than in Kyenjojo. Mother's parity, place of residence, and malaria infection had significant association 
with anaemia in pregnancy. Routine screening for anemia, malaria, and other risk factors should be part of ANC to identify those at risk and prompt management provided to curb their negative consequences.

\section{Acknowledgements}

Sincere gratitude goes to my supervisor Prof Femi Rufus TINUOLA at Federal University, Gusau Zamfara State Nigeria, for his genuine

\section{References}

[1] McLean E et al., 2009. Worldwide prevalence of anaemia, WHO Vitamin and Mineral Nutrition Information System, 1993-2005, Public Health Nutrition, vol. 12, no. 4, pp. 444-454.

[2] WHO 2008. Worldwide Prevalence of Anaemia 1993-2005: WHO Global Database on Anaemia, World Health Organization, Geneva Available from: http://whqlibdoc.who.int/publications/2008/9789241 596657_eng.pdf.

[3] Susan T and Blackburn D.O, 2007. Maternal, Fetal, \& Neonatal Physiology, Clinical Perspective. Qualitative Health Research, vol. 11, no. 6, pp. 780794. Available from:

https://www.elsevier.com/books/maternal-fetal-andneonatal-physiology/blackburn/978-0-323-44934-2.

[4] UNICEF WHO, Maternal Mortality in 2005 Estimates Developed by WHO, UNICEF, UNFPA and World Bank, WHO, Geneva, Switzerland. Available from:

https://apps.who.int/iris/handle/10665/43807.

[5] Liyew A.M, et al., 2021. Prevalence and determinants of anemia among pregnant women in East Africa; A multi-level analysis of recent Demographic and Health Surveys. PLoS One. 16(4): e0250560. doi: 10.1371/journal.pone.0250560. https://www.ncbi.nlm.nih.gov/pmc/articles/PMC807 $8763 /$.

[6] Nyamu G.W et al., 2020. Prevalence and risk factors associated with asymptomatic Plasmodium falciparum infection and anemia among pregnant women at the first antenatal care visit: A hospitalbased cross-sectional study in Kwale County, Kenya. PLoS One. 15(10): e239578. doi: 10.1371/journal.pone.0239578. and intellectual advice in this study. I am grateful to the study participants for voluntarily involvement and for providing the required information. Finally, thanks go to midwives and laboratory technicians in the study sites for their support.

\section{Conflict of Interest}

The authors declare no conflicts of interest in this work.

[7] Mlugu E.M, et al., 2020. Prevalence and Correlates of Asymptomatic Malaria and Anemia on First Antenatal Care Visit among Pregnant Women in Southeast, Tanzania. International Journal Environmental Research and Public Health. 17(9):3123.30. doi: 10.3390/ijerph17093123.

[8] Okube, O.T, et al., 2016. Prevalence and Factors Associated with Anaemia among Pregnant Women Attending Antenatal Clinic in the Second and Third Trimesters at Pumwani Maternity Hospital, Kenya. Open Journal of Obstetrics and Gynecology, 6, 1627. http://dx.doi.org/10.4236/ojog.2016.61003.

[9] UDHS. Uganda Bureau of Statistics (UBOS) and ICF. 2016. Uganda Demographic and Health Survey 2016. Kampala, Uganda, and Rockville, Maryland, USA: UBOS and ICF; 2016. Available from: https://dhsprogram.com/pubs/pdf/FR333/FR333.pdf. [10]Baker SJ and DeMaeyer EM, 1979. Nutritional anemia: it's understanding and control with special reference to the work of the world health organization. The American Journal of Clinical Nutrition; 32(2):368-417. https://doi.org/10.1093/ajcn/32.2.368.

[11] Asrie F, et al., 2017. Prevalence of anemia and its associated factors among pregnant women receiving antenatal care at Aymiba Health Center, northwest Ethiopia. Journal of blood medicine, 8, 3540. https://doi.org/10.2147/JBM.S134932.

[12] Bongomin F, et al., 2021. Anemia in Ugandan pregnant women: a cross-sectional, systematic review and meta-analysis study. Tropical Medical Health. 49: 19. Available from: https://tropmedhealth.biomedcentral.com/articles/10. 1186/s41182-021-00309-z.

[13] Obai G, et al., 2016. Prevalence of anaemia and associated risk factors among pregnant women 
attending antenatal care in Gulu and Hoima Regional Hospitals in Uganda: A cross-sectional study. BMC Pregnancy Childbirth:;16(1):1-7.

https://bmcpregnancychildbirth.biomedcentral.com/t rack/pdf/10.1186/s12884-016-0865-4.pdf.

[14] Ononge S, et al., 2014. Campbell O, Mirembe F. Haemoglobin status and predictors of anaemia among pregnant women in Mpigi, Uganda. BMC research notes, 7, 712. Available from: https://pubmed.ncbi.nlm.nih.gov/25304187/.

[15] WHO catalogue of indicators for health monitoring. SCHI Unit. Division of Epidemiological Surveillance and Health Situation and Trend Analysis. World Health Organization; Geneva: 1996. April 1993. Available from: https://apps.who.int/iris/handle/10665/63030.

[16] Goonewardene M, et al., 2012. Anaemia in pregnancy. Best practice \& research. Clinical obstetrics \& gynaecology, 26(1), 3-24. Available from: https://pubmed.ncbi.nlm.nih.gov/22138002/.

[17] Kibret K.T, et al., 2019. Spatial distribution and determinant factors of anaemia among women of reproductive reproductive age in Ethiopia: a multilevel and spatial analysis. BMJ Open. e027276. doi: 10.1136/bmjopen-2018-027276. Available from: https://pubmed.ncbi.nlm.nih.gov/30948614/.

[18]Buseri, F. I, et al., 2008. Prevalence and risk factors of anaemia among pregnant women in Nigeria. Open Journal of Hematology, vol. 2, pp. 14 19. Available from:

https://benthamopen.com/ABSTRACT/TOHJ-2-14. [19] Alem M, et al., 2013. Prevalence of Anemia and Associated Risk Factors among Pregnant Women Attending Antenatal Care in Azezo Health Center Gondar Town, Northwest Ethiopia. Journal of Interdisciplinary Histopathology. 1(3): 137-144 doi: 10.5455/jihp.20130122042052. Available from: https://www.bibliomed.org/?mno=31063.

[20] Nankinga, O and Aguta, D. 2019. Determinants of Anemia among women in Uganda: further analysis of the Uganda demographic and health surveys. $B M C$ Public Health 19, 1757. Available from: https://bmcpublichealth.biomedcentral.com/articles/ 10.1186/s12889-019-8114-1.

[21] Mahamoud N.K, et al., 2020. Prevalence of anemia and its associated socio-demographic factors among pregnant women attending an antenatal care clinic at kisugu health center IV, Makindye Division, Kampala, Uganda. Journal of blood medicine. 11:138. Available from: https://pubmed.ncbi.nlm.nih.gov/32021527/.

[22] Okia C.C, et al., 2019. Prevalence, Morphological Classification, And Factors Associated with Anaemia Among Pregnant Women Accessing Antenatal Clinic at Itojo Hospital, Southwestern Uganda. Journal of blood medicine, 10, 351-357. Available from: https://pubmed.ncbi.nlm.nih.gov/31695541/.

[23] Kassa, G. M. et al., 2017. Prevalence and determinants of anemia among pregnant women in Ethiopia; a systematic review and meta-analysis. BMC hematology, 17. https://doi.org/10.1186/s12878-017-0090-z.

Available from:

https://www.ncbi.nlm.nih.gov/pmc/articles/PMC564 $6153 /$.

[24] Mahfouz A., et al., 1994. Anemia among pregnant women in the Asir region, Saudi Arabia: an epidemiologic study. The Southeast Asian journal of tropical medicine and public health, 25(1), 84-87. Available from:

https://pubmed.ncbi.nlm.nih.gov/7825031/.

[25] Balarajan Y et al., 2011. Anaemia in low-income and middle-income countries. Lancet.;378 (9809):2123-2135. doi:10.1016/S01406736(10)62304-5. Available from: https://pubmed.ncbi.nlm.nih.gov/21813172/.

[26]Economic Development Policy and Research Department. Poverty status report 2014: Structural Change and Poverty Reduction in Uganda. Kampala: Ministry of finance, planning and economic development; 2014.

https://www.ug.undp.org/content/uganda/en/home/li brary/human_development/TheUgandaPovertyStatu sReport2014.html.

[27] Apili F, et al., 2020. Hookworm Infection among Pregnant Women at First Antenatal Visit in Lira, Uganda: A Cross-Sectional Study. International Journal of Reproductive Medicine. doi: 10.1155/2020/8053939. Available from: https://www.hindawi.com/journals/ijrmed/2020/805 3939/. 
[28] Desai M, et al., 2007. Epidemiology and burden of malaria in pregnancy. The Lancet. Infectious diseases, 7(2), 93-104. https://doi.org/10.1016/S1473-3099(07)70021-X.

[29] Shulman C.E, et al., 2002. Malaria as a cause of severe anaemia in pregnancy. Lancet.; 360:494. Available from:

https://www.thelancet.com/journals/lancet/article/PII S0140-6736(02)09662-9/fulltext.

[30] Shulman C.E and Dorman E.K, 2003. Importance and prevention of malaria in pregnancy.

Transactions of the Royal Society of Tropical Medicine and Hygiene, 97(1):30-5. https://pubmed.ncbi.nlm.nih.gov/12886801/.

[31] Muhangi L et al., 2007. Associations between mild-to-moderate anaemia in pregnancy and helminth, malaria, and HIV infection in Entebbe, Uganda. Transactions of the Royal Society of Tropical Medicine and Hygiene, 101(9), 899-907. https://doi.org/10.1016/j.trstmh.2007.03.017.

[32] Kare A.P and Gujo A.B, 2021. Anemia among Pregnant women attending Ante Natal Care Clinic in Adare General Hospital, Southern Ethiopia: Prevalence and Associated Factors. Health Services Insights. 14: doi: 10.1177/11786329211036303. Available from:

https://www.ncbi.nlm.nih.gov/pmc/articles/PMC832 $7009 /$.
[33] Fondjo L.A, et al., 2020. A multicenter study of the prevalence and risk factor of malaria and anaemia among pregnant women at first antenatal care visit in Ghana. PLoS One. 15(8): e0238077 doi: 10.1371/journal.pone.0238077. Available from: https://www.ncbi.nlm.nih.gov/pmc/articles/PMC744 $4479 /$.

[34] Adam I, Ibrahim Y and Elhardello O, 2018. Prevalence, types, and determinants of Anaemia among pregnant women in Sudan: a systematic review and meta-analysis. BMC Hematology. doi: 10.1186/s12878-018-0124-1. Available from: https://www.ncbi.nlm.nih.gov/pmc/articles/PMC622 $5563 /$.

[35] White N. J. 2018. Anaemia and malaria. Malaria Journal, 17(1), 371. https://doi.org/10.1186/s12936018-2509-9. Available from: https://malariajournal.biomedcentral.com/track/pdf/1 0.1186/s12936-018-2509-9.pdf.

[36] Sadeghian, M., Fatourechi, A., Lesanpezeshki, M., \& Ahmadnezhad, E. 2013. Prevalence of anemia and correlated factors in the reproductive-age women in rural areas of tabas. Journal of family \& reproductive health, 7(3), 139-144. Available from: https://www.ncbi.nlm.nih.gov/pmc/articles/PMC406 $4781 \%$. 